\title{
关于等距曲线的有理参数化 *
}

近年来关于等距线的表示引起了人们的 关注 ${ }^{[1,2]}$. Farouki 和 Sakkalis 提出了一类曲 线, 称为 $P H$ 曲线 (Pythagorean Hodograph curve), 它的等距线可表示成有理形式 ${ }^{[2]}$. 吕 伟证明了平面三次曲线仅当有尖点或为 $P H$ 曲线时才有分段有理参数化的等距线 ${ }^{1}$. 本 文将给出一个充要条件来刻划更一般的但也 具有这一性质的参数曲线.

定义在 $m$ 维欧氏空间中的参数多项式 曲线 $p(t)=\left(x_{1}(t), \cdots, x_{m}(t)\right)$ 称为广义 $P H$ 曲 线, 如果存在一个有理参数变换 $t=\frac{f(u)}{g(u)}$ 和 有理多项式 $R(u)$ 使得

$$
\left\|\boldsymbol{p}^{\prime}(t)\right\|^{2}=\sum_{j=1}^{m}\left(x_{j}^{\prime}(t)\right)^{2}=R^{2}(u),
$$

其中 $f(u)$ 与 $g(u)$ 没有公因式.

定理 1 参数多项式曲线 $\boldsymbol{p}=\boldsymbol{p}(t)$ 为 广义 $P H$ 曲线的充要条件是 $\left\|p^{\prime}(t)\right\|^{2}=\tau^{2}(t)$ $\left(a t^{2}+b t+c\right)$, 其中 $\tau(t)$ 为多项式, $a, b$ 和 $c$ 为 实数.

关键证明必要性. 容易验证 $\left\|\boldsymbol{p}^{\prime}(t)\right\|^{2}$ 可 作如下分解:

$$
\left\|\boldsymbol{p}^{\prime}(t)\right\|^{2}=\omega^{2}(t) \cdot\left[\left(t-a_{1}\right)^{2}+b_{1}^{2}\right] \cdots\left[\left(t-a_{k}\right)^{2}+b_{k}^{2}\right],
$$

其中 $\omega(t)$ 为多项式, $a_{j}, b_{j}$ 为实数, $b_{j} \neq 0$, 且当 $j \neq l$ 时, $\left(a_{j}, b_{j}\right) \neq\left(a_{l}+b_{l}\right)$. 于是下面只需证明 $k \leqslant 1$. 若不然, 设 $k>1$, 因为存在 $t=\frac{f(u)}{g(u)}$ 使得 (1) 式成立, 故必有一个多项式 $q(u)$, 满 足

$$
\begin{aligned}
& {\left[\left(f(u)-a_{1} q(u)\right)^{2}+b_{1}^{2} g^{2}(u)\right] \cdots\left[\left(f(u)-a_{i} g(u)\right)^{2}\right.} \\
& \left.\quad+b_{k}^{2} g^{2}(u)\right]=\dot{q}^{2}(u) .
\end{aligned}
$$

对于 $q(u)$ 的每一个根 $u_{r}$, 它必为复根, 且 $u_{r}$ 和 它的共轭必为且仅为某一 $\left(f(u)-a_{i} q(u)\right)^{2}+$ $b_{i}^{2} g^{2}(u)$ 的偶数重根. 于是我们可以证明存在 两个互素的多项 $v_{1}(u)$ 和 $v_{2}(u)$ 使得

$$
\begin{gathered}
\left(f(u)-a_{j} g(u)\right)^{2}+b_{j}^{2} g^{2}(u)=v_{j}^{2}(u), \quad j=1,2 . \\
\text { 令 } \\
\bar{x}(t)=\frac{t^{3}}{3}-\frac{a_{1}+a_{2}}{2} t^{2}+\left(a_{1} a_{2}-b_{1} b_{2}\right) t, \\
\bar{y}(t)=\frac{b_{1}+b_{2}}{2} t^{2}-\left(a_{1} b_{2}+a_{2} b_{1}\right) t,
\end{gathered}
$$

曲线 $c_{2}:(\bar{x}(t), \bar{y}(t))$ 为一平面三次参数多项 式曲线, 无尖点也非 $P H$ 曲线, 但 $\bar{x}^{\prime 2}(t)+\bar{y}^{\prime 2}(t)$ $=v_{1}^{2}(u) v_{2}^{2}(u) / g^{4}(u)$, 即其等距线可有理参数化, 与 (1) 式中结果矛盾, 这就证明了必要性.

显然, 对于平面上的广义 $P H$ 曲线, 其等 距线可分段精确地表示为有理参数形式. 进 一步地, 我们有

定理 2 平面有理参数曲线 $p(t)=\frac{Q(t)}{\omega(t)}$ 可通过一个有理参数变换 $t=\frac{f(u)}{g(u)}$ 使它的 等距线为关于 $u$ 的分段有理曲线当且仅当 $\left\|\boldsymbol{Q}^{\prime} \cdot \omega-\boldsymbol{Q} \cdot \omega^{\prime}\right\|^{2}=\tau^{2}(t) \cdot\left(a t^{2}+b t+c\right)$.

\section{参考文献}

[1] Pham, B., Comput. Aided Design, 1992, 24: 223-229.

[2] Farouki, R., Sakkalis, T., IBM J. Res. Develop., 1990, 34: 736.

\section{郑建民}

(浙江大学应用数学系, 杭州 310027)

* 国家自然科学基金资助项目.

1) Lü Wei, Rational offsets by reparametrizations, reprint. 